\title{
Letter to the Editor regarding "Quantification of Paraquat, MPTP, and MPP+ in brain tissue using microwave-assisted solvent extraction (MASE) and high-performance liquid chromatography-mass spectrometry"
}

\author{
Brian Buckley \\ Received: 19 September 2012 / Accepted: 15 October 2012 /Published online: 9 November 2012 \\ (C) Springer-Verlag Berlin Heidelberg 2012
}

\section{Don't kill the messenger}

In 2009, a paper was published in this journal describing new methods for extraction and analysis of paraquat, MPTP, and MPP+ using microwave extraction and LC/ MS/MS quantitation [1]. These compounds are important in mouse models of Parkinson's disease. One of the paper's co-authors, Mona Thiruchelvam, was recently admonished for scientific misconduct [2] and had to withdraw two of her dozen or so papers on the behavior of treated mice because she reused image data on brain segments. Under normal circumstances, I would not draw attention to her role on the aforementioned paper published here but individuals who are more concerned with personal attack than scientific integrity are using Dr. Thiruchelvam's role on the paper published here to try and besmirch the reputation of other co-authors. As the corresponding author of the ABC paper, I felt it necessary to set the record straight. Dr. Thiruchelvam provided samples and a write-up of how the samples were created (type of animal, dosing, etc.) and nothing more. She had

\section{B. Buckley $(\bowtie)$}

Rutgers University-EOHSI,

170 Frelinghuysen Road,

Piscataway, NJ 08854, USA

e-mail: bbuckley@eohsi.rutgers.edu no role in the analysis method, either here or at CDC and her limited participation does not affect the quality of the work published here.

As analysts, we are often the target of those who have an agenda because we are the messengers of bad news for someone, either those hoping we will find something in a sample or those hoping we do not. Our principal role is to make the measurement and to the best of our ability provide information about its precision and accuracy. We will never know the outcome of Dr. Thiruchelvam's studies that were withdrawn, but they had nothing to do with the work presented here. Anyone who would imply that her participation in this work impugns the integrity of the other investigators clearly has a secondary agenda. I am disappointed that this letter had to be written, but I am thankful to have the opportunity to explain the situation in greater detail. As analysts, we provide the data and I encourage all to remember that whether the information is good or bad, from your viewpoint, don't kill the messenger.

\section{Reference}

1. Winnik B, Barr DB, Thiruchelvam M, Montesano MA, Richfield EK, Buckley B (2009) Anal Bioanal Chem 395:195-201

2. Dunning H, Parkinson's Researcher Fabricated Data, The Scientist, June 29, 2012 